OPEN ACCESS

Edited by: Andrzej Klimczuk,

Warsaw School of Economics, Poland

Reviewed by:

Martin Thomas Falk,

University of South-Eastern Norway,

Norway

Mohammad Amiryousefi,

University of Isfahan, Iran

*Correspondence:

Santosh Kumar

ksantosh@uthsc.edu

Specialty section:

This article was submitted to

Organizational Psychology,

a section of the journal

Frontiers in Psychology

Received: 06 July 2020

Accepted: 16 October 2020

Published: 09 November 2020

Citation:

Kumar S, Kodidela S, Kumar A Gerth K and Zhi K (2020) Intervention and Improved Well-Being of Basic Science Researchers During the COVID 19 Era: A Case Study.

Front. Psychol. 11:574712. doi: 10.3389/fpsyg.2020.574712

\section{Intervention and Improved Well-Being of Basic Science Researchers During the COVID 19 Era: A Case Study}

\author{
Santosh Kumar ${ }^{1 *}$, Sunitha Kodidela ${ }^{1}$, Asit Kumar ${ }^{1}, K_{\text {Kelli Gerth }}{ }^{1}$ and Kaining Zhi ${ }^{2}$ \\ ${ }^{1}$ Department of Pharmaceutical Sciences, College of Pharmacy, University of Tennessee Health Science Center, Memphis, \\ TN, United States, ${ }^{2}$ The Plough Center of Drug Delivery Solutions, University of Tennessee Health Science Center, Memphis, \\ TN, United States
}

The coronavirus disease-19 (COVID-19) pandemic has affected individuals of all categories, irrespective of their geographical locations, professions, gender, or race. As a result of full or partial lock-down and stay-at-home orders, the well-being and productivity of individuals were severely affected. Since basic science research requires laboratory experiments, the work-from-home strategy hurt their productivity. In addition, the combination of decreased productivity and staying at home is likely to compromise their well-being by causing stress and anxiety. In this case study, a strategy was developed to engage researchers through listening and learning, motivation, and empowerment, using regular virtual sessions. Through these virtual sessions, research work was prioritized and coordinated, from idea conception to writing research papers and grant proposals. Perceived stress scores (PSS) and COVID-19-related stress (COVID-SS) scores were measured to evaluate general and COVID-19-induced stress, respectively, every month from March to July 2020 during the COVID-19 era. The result showed a significant improvement in both the PSS and the COVID-SS scores of the intervention group compared to the control group. In addition, while there was no/minimal change in PSS and COVID-SS scores from March to subsequent months until July for the control group, the intervention groups showed significant and consistent improvement in both scores in the intervention group. Overall, the intervention strategy showed improved well-being for basic science researchers, which was also consistent with their improved productivity during the COVID-19 era.

Keywords: COVID-19, productivity, perceived stress score, laboratory research, well-being

\section{INTRODUCTION}

The coronavirus disease-19 (COVID-19) pandemic is an ongoing world crisis. This pandemic has taken a toll on human health and has also placed a huge burden on economies, societies, and families across the globe (Carter et al., 2020; Cutler, 2020; Donthu and Gustafsson, 2020; Hua et al., 2020; Jenson, 2020; Mclaren et al., 2020; Ornell et al., 2020; Power, 2020; Satiani et al., 2020). This COVID-19 crisis is further deepened because the future of countries, societies, and individuals is 
uncertain and unpredictable in the months and perhaps years to come. A recent special issue on COVID-19 by "Taloy and Francis" describes the impact of this pandemic on, "Emerging markets finance and trade," which ultimately causes stress in world economies and societies (Taylor and Francis, 2020). In addition to the impact on world economies, world trade has experienced a massive contraction as a result of a drastic reduction in trade connectivity and commercial activities among countries during COVID-19 outbreak (Vidya and Prabheesh, 2020). The trade forecast among the major trading countries further Shows a decline until December 2020. However, it is worth mentioning that amid the COVID-19 pandemic, there is a significant improvement in air quality, though temporarily, and a positive macroeconomic response has been seen in some countries such as China and India during the COVID-19 outbreak (Ming et al., 2020). The impact on global economies and loss of millions of jobs have been one of the major causes of stress and anxiety among global populations.

The impact of the COVID-19 pandemic on human health, which caused $\sim 38$ million infections and $>1$ million deaths world-wide as of October 15, 2020, far exceeds the impact of previous epidemics or pandemics in recent history (CoronavirusResources-Center, 2020). Although over $90 \%$ of people recovered from the infection/disease, many individuals suffered from multiple organ damage (lungs, kidney, liver, heart, etc.) (Renu et al., 2020; Spuntarelli et al., 2020). Further, a large number of recovered populations from COVID-19 also suffered from mental and psychological diseases/conditions such as stress, anxiety, and depression (Salari et al., 2020; Xiong et al., 2020). Studies have shown that $\sim 50 \%$ of individuals who recovered from COVID-19 are diagnosed with depression, and $\sim 40 \%$ are diagnosed with anxiety and stress (Rogers et al., 2020). Individuals associated with COVID-19 patients, and others, especially those who have lost their jobs and are experiencing financial crises, also show symptoms of depression, anxiety, and stress (Dubey et al., 2020; Titov et al., 2020).

This is the first time in modern history that almost all countries, either fully or partially, enter into a lock-down phase and enforce stay-at-home orders (Asensio et al., 2020). One of the major health concerns, as a result of lock-down and stayat-home orders, is the mental health of individuals who stay at or work from home (Killgore et al., 2020). Stress and anxiety are usual reactions to any unpredictable pandemic situation. As a result of stress due to the COVID-19 pandemic, the general population, particularly health care professionals and college students, experienced changes in concentration, anxiety, irritability, and eventually reduced productivity (Tangen et al., 1981; Kecojevic et al., 2020; Ozamiz-Etxebarria et al., 2020; Stanton et al., 2020; Wu et al., 2020). These studies suggest a need to develop mitigation and psychological intervention strategies that can improve the mental health of the general population during the COVID-19 era, especially in vulnerable groups such as health professionals and college students. To the best of our knowledge, there is no study conducted among basic science researchers to examine the impact of the COVID-19 epidemic on psychological health and stress or the relationship of these factors to productivity. Therefore, we conducted a case study on intervention and well-being of basic science researchers at the University of Tennessee Health Science Center (UTHSC).

Research laboratories at UTHSC were closed for all nonemergency work in March, and the researchers were asked to work from home (UTHSC, 2020). Although manuscripts and grant writing could be done from home, it is very difficult to stay productive if experiments in the basic science laboratory are completely stalled. Basic science experiments take 1-2 weeks to wrap up and equally the same time to restart. Thus, until the research laboratories partially opened in the first week of June, employees had lost 3 months of complete followed by 2 months (June-July) of partial basic science research. In addition to reduced productivity, the work-from-home plan for researchers who normally work in a laboratory setting can increase stress and anxiety. Compounded by COVID-19-related stress, this has the potential to further reduce productivity. Moreover, due to uncertainty surrounding lab reopening dates, researchers were also uncertain about their career progression. All these factors may contribute to a lack of concentration, irritability, insomnia, and reduced productivity among scholars.

The objective of the present study is to design an interventional strategy to mitigate stress and maintain well-being and productivity for basic science researchers during the workfrom-home order in the COVID-19 era. The mitigation strategy is to plan and implement necessary experiments during the prelock-down period, followed by engaging in idea development, data analysis, and manuscript writing, as well as engaging in listening and empowering sessions via virtual lab meetings during and after the lock-down periods. The hypothesis is that the interventional strategy will significantly reduce stress and improve the well-being of basic science researchers while maintaining their productivity. To assess the well-being of subjects, Perceived Stress Score (PSS) and COVID-19-related stress scores (COVID-SS) were measured. Generally, the stress levels of health care professionals and college students are measured using the PSS method (Du et al., 2020; Georgiou et al., 2020; Guo et al., 2020; Meira et al., 2020; Zarghami et al., 2020), which is the most widely used method to monitor perceived stress (New Hampshire Department of Administrative Services, 2020). However, to measure the stress, anxiety, and overall well-being of individuals specifically induced by COVID-19-related changes in lifestyle and altered productivity, the PSS method may not be sufficient. Therefore, we used the COVID-19 stress related score (COVID-SS) to assess the fear, learning, and growth in knowledge of individuals during the pandemic (Epilepsy Society, 2020). The current study results suggest an improved well-being of the intervention group compared to the control group, which is also consistent with the reduced stress and improved productivity of the intervention group.

\section{METHODS}

\section{Preparation Before the Crisis for Intervention Group}

When the WHO declared COVID-19 a Public Health Emergency of International Concern on 30 January 2020 (Patel et al., 2020), 
a strategic plan for researchers in our group was put-together. The strategic plan included: (1) postponing manuscript writing and other paper work and performing wet-lab experiments to obtain data until the lab was closed in the second week of March, (2) data analysis and manuscript writing during the work-fromhome orders from mid-March to May 31 and until July 31 during partial lab-closure, (3) conceiving new ideas and writing manuscripts for review papers, as well as writing grant proposals for the same periods. To make the researchers accountable for their productivity, a $2 \mathrm{~h}$ virtual lab meeting every Monday and one-on-one virtual meetings as needed were implemented. The demographics of the intervention group was 4 men and 5 women that included 3 students, 2 post-doctorate fellows, 3 research staffs, and 1 faculty. The study population was generally healthy and their age ranged approximately from 22 to 50 years. Since the intervention requires a certain supervisory relationship among all participants, it is not feasible to increase group size. Inviting researchers from other research groups may result in a conflict of interest among principle investigators since most research groups are independent. Hence, we could include only nine people in the intervention group.

\section{Implementation During the Crisis}

A modified anonymous strategy was used as an intervention. Almost half of each lab meeting until May 31 was spent in listening to everyone's concerns, celebrating any good news, and COVID-19-related facts from reliable sources. The frequency of these discussions was reduced when the laboratory was partially opened from June 1 to July 31. In general, the strategy was to learn from each other and empower each other. During the laboratory meetings, some engaging games were also played to overcome stress. The empowering sessions were developed based on vast knowledge, emotional intelligence, and the experience of our diverse group, as well as available literatures (World Health Organization, 2004; Shultz et al., 2016; Hendriks et al., 2017; Seyedin et al., 2019; Jiménez et al., 2020; Schlesselman et al., 2020). We compiled the following discussion topics to empower each other.

(1) COVID-DIFFERENTIATOR (COVID-DIFF): Similar to any crisis, COVID would differentiate people into three categories: (1) Individuals who were negatively impacted (with no mistake of theirs), (2) individuals who stayed the course and were able to handle well, and (3) individuals who found new opportunities and improved performance. In general, most people, including our study participants, belong to categories 1 and 2. Our goal was to empower them with the below mentioned strategies, which could help them to move to category 3 .

(2) Faith/dreams vs. Panic/fear: The intervention group discussed the pros and cons of having faith/dreams vs. feeling panic/fear, with numerous examples. These empowered each other to have faith and dreams.

(3) Facts/reality vs. Opinion/hype: The intervention group was advised to follow facts and reality and educate others with these rather than uncorroborated opinions and hype.
(4) Safety vs. Carelessness: The intervention group was educated to exercise safety and caution by following the COVID-19 policies and guidelines of national and local organizations.

(5) Managing the crisis vs. Getting under the crisis: The intervention group discussed various aspects of the crisis and how one can manage the crisis, rather than getting under the crisis, in a way that negatively impacts us.

(6) Thriving vs. Surviving: Finally, the intervention group discussed how to thrive during the crisis and not just survive. As Stanford economist Paul Romer once stated, "a crisis is a terrible thing to waste" (Chisholm-Burns, 2010). The intervention group as a whole decided, "we will not let the crisis go to waste." The group discussed various ways to improve productivity and manage stress during the crisis. For example, ways to improve grit and mental toughness by acquiring positive attitudes and selfdiscipline were discussed. Besides, performing physical and mental activities, such as walking/running/exercising, yoga, and meditation were promoted in group discussion.

In addition to the above empowering sessions, the intervention group also discussed the following advantages of working from home.

(1) Freedom: freedom to work with a chosen time, place, and uniform.

(2) Family together: opportunity to spend quality and quantity time with families.

(3) Time to think creatively: compared to lab and office environments, work-from-home may give a change in environment, more time, and quietude to think creatively.

(4) Yoga and Meditation: a home environment may empower people to do yoga and meditation to maintain physical and mental health.

(5) Opportunity to take care of the backlog, start new writing projects, and contribute to society: working from home may give more time for data analysis, writing manuscripts, and initiating new projects for review papers and/or grant proposals. It can also motivate and empower society, which is going through a difficult time, through messages via reliable sources.

Finally, as a group and as individuals, the intervention group did reflection exercises on the following things. (1) How have I contributed positivity or negativity to others? (2) Does someone feel better after an interaction with me vs. how they felt before? (3) Did shared interest rise above self-interest? (4) Did I listen more - or talk more? (5) How many times today did I complain about someone or something? (6) How many times did I simply say thank you? (7) What did I learn this week, especially that challenged my thought processes? (8) What did I do this week, especially that is unique and out-of-norms?

\section{Control Group}

A control group of UTHSC basic science researchers, which did not go through the intervention as described above, is included in this study. The control group consists of 6 students, 
3 post-doctorate fellows, and 1 research scientist ( 5 men and 5 women). The participants were generally healthy and their age ranged approximately from 25 to 40 years. The control group of basic science researchers also went through similar challenges at UTHSC due to complete lab-closure from mid-March to May 31 and partial lab-closure from June 1 to July 31.

\section{OUTCOME MEASURES}

Two outcomes were measured during the 5-month period. The PSS and COVID-SS outcomes were measured by using their respective surveys upon an Institutional Review Board (IRB) approval from the University of Tennessee Health Science Center.

\section{Perceived Stress Score (PSS)}

The PSS of nine participants from the intervention group and ten participants from the control group for the months of March-July were measured, upon their consent to do a volunteer survey. PSS is the most-widely used method to measure stress levels in occupational health, especially among professional students in health science. This method was essentially used as described (New Hampshire Department of Administrative Services, 2020). In brief, PSS was measured by self-scoring the following questions. Scoring was performed (between 0 and 4; 0 being never and 4 being very often), followed by reversing the scores of questions $4,5,7$, and 8 , and then adding all the scores. Scores with $0-13,14-26$, and 27-40 are defined as low, moderate, and high stress, respectively. The group PSS scores were then analyzed longitudinally for the months of April-July, using March as control month, as the intervention began in April. COVID-SS scores for the intervention group were also compared and analyzed from the control group for each month.

\section{COVID-19-Related Stress Scores (COVID-SS)}

The COVID-SS of nine intervention participants and ten control participants for the months of March-July were also measured upon their consent to do a volunteer survey. COVID-SS is a new method that used to assess the stress level of participants during the COVID-19 era using their behaviors and actions in three zones (fear, knowledge, and growth). This method was essentially used as described previously (Manch, 2020). In brief, the questions/statements, as presented in Table 1, were used to self-assess the three zones: fear, knowledge, and a growth mindset. Every correct statement for each zone carries one point. The total points for each zone represent the mindsets and attitudes of participants in terms of COVID-19-related fear, knowledge, and growth. The information obtained from these zones can then be correlated with COVID-19-induced stress and overall well-being of participants. The group COVID-SS scores were then analyzed longitudinally for the months of April-July, using March as the control month, as the intervention began in April. The COVID-SS scores for the intervention group were also compared and analyzed from the control group for each month.
TABLE 1 | Statements used to score COVID-SS for each zone. Each correct statement carries 1 point.

\begin{tabular}{|c|c|c|}
\hline $\begin{array}{l}\text { Fear zone (total } 5 \\
\text { points) }\end{array}$ & $\begin{array}{l}\text { Knowledge zone (total } \\
7 \text { points) }\end{array}$ & $\begin{array}{l}\text { Growth zone (total } 8 \\
\text { points) }\end{array}$ \\
\hline $\begin{array}{l}\text { I grab food, medications, } \\
\text { and toilet paper that I } \\
\text { don't need }\end{array}$ & $\begin{array}{l}\text { I start to give up what I } \\
\text { can't control }\end{array}$ & $\begin{array}{l}\text { I think of others and know } \\
\text { how to help them }\end{array}$ \\
\hline $\begin{array}{l}\text { I spread emotions related } \\
\text { to fear and anger }\end{array}$ & $\begin{array}{l}\text { I stop consuming what } \\
\text { hurts me, from food to } \\
\text { news }\end{array}$ & $\begin{array}{l}\text { I make my talents } \\
\text { available to those who } \\
\text { need them }\end{array}$ \\
\hline I complain frequently & I identify my emotions & $\begin{array}{l}\text { I live in the present and } \\
\text { focus on the future }\end{array}$ \\
\hline $\begin{array}{l}\text { I forward all messages I } \\
\text { receive about COVID-19 }\end{array}$ & $\begin{array}{l}\text { I am aware about the } \\
\text { situations and know how } \\
\text { to act }\end{array}$ & $\begin{array}{l}\text { I am empathetic to myself } \\
\text { and to others }\end{array}$ \\
\hline \multirow[t]{4}{*}{ I get mad easily } & $\begin{array}{l}\text { I evaluate information } \\
\text { before spreading false }\end{array}$ & $\begin{array}{l}\text { I thank and appreciate } \\
\text { others }\end{array}$ \\
\hline & $\begin{array}{l}\text { I recognize that we all are } \\
\text { trying to do our best }\end{array}$ & $\begin{array}{l}\text { I keep a happy emotional } \\
\text { state and give hope }\end{array}$ \\
\hline & & $\begin{array}{l}\text { I look for a way to adapt } \\
\text { to changes }\end{array}$ \\
\hline & & $\begin{array}{l}\text { I practice quietude, } \\
\text { patience, relationships, } \\
\text { and creativity }\end{array}$ \\
\hline
\end{tabular}

\section{Research Productivity}

Our mitigation and empowering strategies were likely to improve the research productivity. It was measured only in our intervention study group in terms of conceiving ideas, data analysis, manuscript writing and submission, manuscript acceptance, and publication, as well as grant submission.

\section{Statistical Analysis}

Mean \pm SEM was calculated and compared to the control group. Student's $T$-test was applied to compare the scores between the intervention and control groups, as well as between the control month (April) and individual intervention months (April-July) for both control and intervention groups. All the statistical calculations were performed using GraphPad Prism 7. $p<0.05$ was considered statistically significant.

\section{RESULTS}

\section{Perceived Stress Score (PSS)}

An intervention group of nine participants and a control group of ten participants volunteered to take the perceived stress test, as described in the outcomes measure section. The Mean $\pm S D$ of the PSS were evaluated, and the relative scores of the intervention group vs. control group were analyzed. Comparison and analysis were also performed in a longitudinal manner, in which March was a control month when the intervention began (Figure 1). Overall, results showed a relatively high PSS (17.4 \pm 2.7) for the intervention group in March, which consistently decreased in the subsequent months, with a statistically significant decrease in June (13.8 \pm 2.3$)$ (Figure 1A). However, the PSS scores did not significantly change in the 

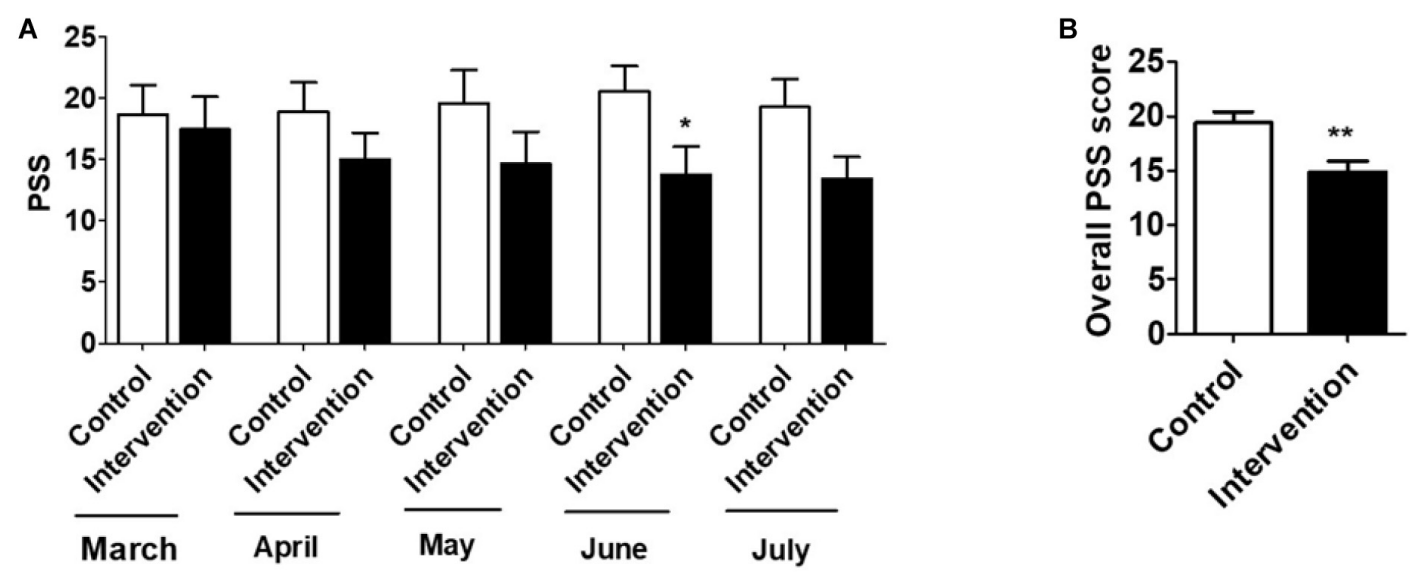

FIGURE 1 | (A) Mean \pm SD of Perceived Stress Score (PSS) of control $(n=10)$ and Intervention ( $n=9)$ groups for March to July. (B) Mean \pm SD of overall PSS of control ( $n=50,10$ subjects for 5 months) and intervention ( $n=45,9$ subjects for 5 months) groups. $T$-test was applied to compare the scores between intervention and control groups. $p<0.05, p<0.01$ are represented as "*” and "**”, respectively when compared the scores between intervention and control groups. "\#" represents $p<0.05$ when compared between intervention groups (March vs. other months). "\$" represents $p<0.05$ when compared between control groups (March vs. other months).

control group from the months March to July. Importantly, there was a statistically significant decrease in the overall PSS scores (March-July combined) of the intervention group compared to the control group $(14.7 \pm 0.8$ vs.19.3 \pm 0.3$)$ (Figure 1B). In general, the intervention group showed an increased stress level (moderate stress) in March, which was subsequently decreased to low stress in the subsequent months. However, the stress level in the control group remained moderate throughout these 5 months. Since the PSS method is used to measure general stress levels, in the following section we used COVID-19-related stress scores in our participants and determined whether intervention group had a significantly different stress level.

\section{COVID-19-Related Stress Scores (COVID-SS)}

COVID-SS measures three different components (fear, knowledge, and growth zones) as described in the outcomes measure section. This method was used specifically to measure COVID-19-related stress and anxiety. COVID-SS examines whether participants can change their behavior and actions as a result of training and move from the fear zone to the knowledge zone, and ultimately the growth zone, across the 5 months. Nine participants from the intervention group and ten participants from the control group took the COVID-19-related stress test survey. The Mean $\pm S D$ of COVID-SS was evaluated for each zone during the months of March-July. The results from nine intervention participants showed a relatively high COVID-SS for the fear zone $(1.78 \pm 0.52)$ in March, which subsequently decreased in April, with a statistically significant decrease in May $(0.33 \pm 0.23)$, June $(0.55 \pm 0.24)$, and July $(0.33 \pm 0.23)$ (Figure 2A). On the other hand, the COVID-SS for the knowledge zone steadily increased from March to July, with a statistically significant increase in May (5.23 \pm 0.23$)$, June $(5.33 \pm 0.37)$, and July $(5.66 \pm 0.37)$ compared to March
$(3.33 \pm 0.47)$ (Figure 2C). Similarly, the COVID-SS for the growth zone also steadily increased from March to July, with a statistically significant increase in May (6.67 \pm 0.41$)$, June (7.01 \pm 0.16$)$, and July (7.10 \pm 0.26$)$ compared to March $(4.44 \pm 0.62)$ (Figure 2E). On the other hand, compared to march, COVID-SS scores of the control group in the fear zone did not statistically change in the subsequent months (Figure 2A). However, compared to March, COVID-SS scores in July significantly increased in both knowledge (4.80 \pm 0.49 vs. $1.27 \pm 0.42)$ (Figure 2C) and growth (6.01 \pm 0.75 vs. $2.26 \pm 0.75)$ zones (Figure 2E), perhaps due to partial opening of the lab. However, this increase in the knowledge and growth zones for the control group was relatively lower than that of the respective increase in the intervention group.

More importantly, COVID-SS scores of the intervention group in the fear zone were significantly lower than the control group in May $(0.33 \pm 0.22$ vs. $1.47 \pm 0.49)$ and July $(0.33 \pm 0.33$ vs. $1.65 \pm 0.55$ ) (Figure 2A). On the other hand, COVIDSS scores of the intervention group in knowledge zone were significantly higher than the control group in May (5.33 \pm 0.23 vs. $1.13 \pm 0.38$ ) (Figure 2C). Similarly, COVID-SS scores of the intervention group in growth zone were also significantly higher than the control group in May $(6.67 \pm 0.47$ vs. $1.95 \pm 0.65)$ and June (7.01 \pm 0.16 vs. $1.90 \pm 0.63)$ months (Figure 2E). We also analyzed the overall COVID-SS scores for each zone for the months of March-July for both intervention and control groups. The overall COVID-SS scores of the intervention group in the fear zone were significantly lower than the control group $(0.75 \pm 0.26$ vs. $1.74 \pm 0.08)$ (Figure 2B). On the other hand, the overall COVID-SS scores of the intervention group in the knowledge zone were significantly higher than the control group $(4.80 \pm 0.43$ vs. $4.18 \pm 0.21)$ (Figure 2D). Similarly, overall COVID-SS scores of the intervention group in the growth zone were also significantly higher than the control group $(6.13 \pm 0.51$ vs. $4.88 \pm 0.40)$ (Figure $\mathbf{2 F}$ ). Taken together, these findings 

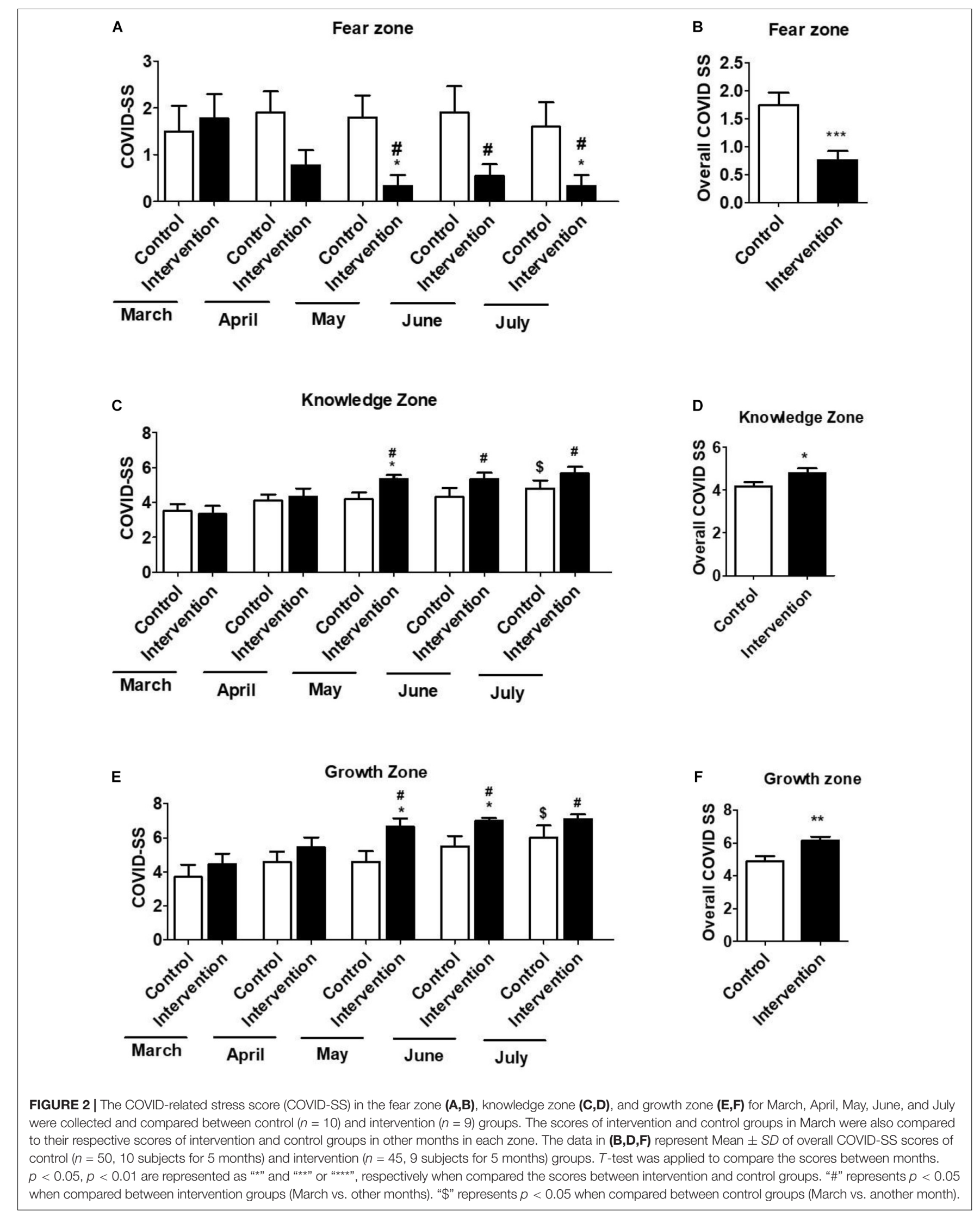
suggest that intervention strategy to deal with COVID-related stress and anxiety significantly and consistently decreased the fear and increased the knowledge and subsequent growth in their knowledge.

\section{Productivity During the COVID-19 Era}

It is widely known that reduced stress enhances productivity, and increased productivity feeds into low stress and improved well-being (Anderzén and Arnetz, 2005; Heylighen and Vidal, 2008). Stress and productivity work as a loop that feed into each other. Therefore, the research productivity was measured in terms of conceiving new ideas for a review paper, data analysis for the original paper, and manuscript writing and their publication in peer-reviewed journals. Since the evidence for only published papers can be provided, the productivity metrics for only published papers are presented in Table 2 . Briefly, the data from a project (Table 2) was analyzed, which was later written and published. Two other manuscripts for original articles were also revised and published during the same time-period. In addition to original articles, 7 review papers and 1 editorial were published between March and the first week of September (Table 2). Two of these review papers are from the field of COVID-19 for which we conceived the idea of the paper during the COVID-19 era.

For the past 5 years, the average peer-reviewed publication rate for the group is 8 per year. Thus, publishing 11 papers in 6 months can be considered higher than the previous productivity for this research group. It has been widely accepted that obtaining data is the most time-consuming step and requires significant manpower. However, in the absence of experiments, optimal priorities and time management were implemented to maximize productivity with an overall exceptional result. The productivity is also considered unique, since two review articles were published on the much-needed field of COVID-19.

In addition to scientific papers, two opinion columns on COVID-19 were published in the Memphis-based "Commercial Appeal," the "USA Today" network, on April 13 (Kumar, 2020b) and on June 11 (Kumar, 2020a). The former opinion column was on, "University of Tennessee Health Sciences Center making strides in treating COVID-19," in which, a scientific opinion on repurposing antiviral drugs was provided. The latter one was on, "Challenges with COVID-19 could bring transformational change, improve human health," in which, a scientific opinion on how COVID-19 could help improve general immunity and reduce the prevalence of chronic diseases was provided.

\section{DISCUSSION}

The present study was designed to mitigate general as well as COVID-19-induced stress in basic science researchers, which subsequently helps to improve the overall well-being and productivity in the intervention group. We used both PSS and COVID-SS methods to measure their stress levels and correlated the improved well-being of the intervention group with their productivity. Overall, findings strongly suggest that the mitigation strategy resulted in reduced stress levels and increased research productivity among basic science researchers during the COVID-19 pandemic. However, the data from the control group suggests that the current COVID-19 pandemic has a significant impact on the mental health of basic science researchers, which is consistent with the impact on mental health in the general population, especially in health care professionals and college students (Tangen et al., 1981; Kecojevic et al., 2020; OzamizEtxebarria et al., 2020; Stanton et al., 2020; Wu et al., 2020).

Overall, the intervention group showed reduced general stress compared to the control group. Our outcome is different from the outcomes derived from the perceived stress and anxiety in the general population, in which this pandemic increased anxiety levels. In one study, high PSS scores among the general population were observed in women, persons under age 30, students, and those who believed themselves to be at a greater risk of contracting the illness (Limcaoco et al., 2020). Additionally, participants' perception of susceptibility to COVID-19 was likely affected by several factors. Participants were not elderly or in other high-risk groups. Further, a certain level of scientific literacy (undergraduate and above) may have equipped the researchers to practice appropriate COVID-related health measures and mitigate COVID-related fear. Moreover, upon comparing with the control group, which were of similar demographics, ages, and education levels, it can be said that the

TABLE 2 | Number of manuscripts written and published during the months of March-July.

\begin{tabular}{|c|c|c|c|c|c|c|}
\hline PMID/DOI/In press & Type of paper & Idea & Data analysis & Manuscript submission & Revision submission & Published \\
\hline PMID 32481515 & Original article & & $x$ & $x$ & $x$ & $x$ \\
\hline PMID 32443728 & Original article & & & & $x$ & $x$ \\
\hline PMID: 32433651 & Original article & & & & $x$ & $x$ \\
\hline PMID 32696265 & Editorial & & & $x$ & & $x$ \\
\hline PMID 32357553 & Review & $x$ & & $x$ & $x$ & $x$ \\
\hline EIDDJ-100021 & Review & $x$ & & $x$ & $x$ & $x$ \\
\hline PMID: 32722629 & Review & & & $x$ & $x$ & $x$ \\
\hline PMID: 32823684 & Review & $x$ & & $x$ & $x$ & $x$ \\
\hline doi: 10.1080/23808993.2020.1812382 & Review & & & & $x$ & $x$ \\
\hline PMID: 32842791 & Review & & & & $x$ & $x$ \\
\hline PMID: 32932786 & Review & & & $x$ & $x$ & $x$ \\
\hline
\end{tabular}

"X" Represent completed task in that particular section. 
strategy to deal with stress during the COVID-19 era has helped to manage stress levels of the researchers.

Intervention study based on the psychological health status of researchers as backline workers could provide a potential statewide measure that could be used by other researchers or even frontline workers to cope with stress during the pandemic outbreak. However, stress assessment and outcome measurements used in our study will be more appropriate for stress management and wellbeing of the mental state among researchers. Inconsistent with our findings, the frontline health care professionals, who were working in proximity to patients admitted in the ICU with severe lung infections, experienced mental health problems with substantial psychological distress (Greenberg et al., 2020). A descriptive study that was performed on health care professionals during COVID-19 revealed a relatively moderate level of perceived stress (PSS mean $=15.71 \pm 4.02$ ) on PSS-10, along with $38 \%$ identified as depressed and $24 \%$ as suffering from anxiety. Health care professionals who experience higher perceived stress than others likely worked at intensive care units (ICUs) (Ma et al., 2020). Findings of a meta-analysis indicated a high psychological impact, not only on healthcare workers (HCW) and patients, but also in the general population (Luo et al., 2020; Pappa et al., 2020). The psychological distress was mediated by anxiety and depression. However, the existence of other variables could be wrongly predicted as stress associated with COVID-19.

In a cross-sectional study conducted on frontline nurses $(n=325), 123$ nurses were found to have a dysfunctional level of anxiety that involves fear, behavior, and psychological distress (Labrague and De Los Santos, 2020; Lee, 2020). Studies conducted on the psychological impact of COVID-19 on frontline nurses have found an overall high prevalence of anxiety ranged between 18 and 92.3\% (Alwani et al., 2020; Luo et al., 2020) that could be averted by providing better organizational and social support, in addition to the implementation of safety measures at the workplace and quality personal protective equipment (PPE) (Labrague and De Los Santos, 2020). Overwhelming workload and lack of sleep may also contribute to the mental burden of frontline workers (Lai et al., 2020) that could be considered during the assessment of their stress levels. In general, healthy people were found to be less affected by COVID19 related stress compared to those with anxiety-related or mood disorders in the population-based study conducted in the US and Canada (Asmundson et al., 2020). A cross-sectional survey based on modified PSS-10 conducted on 406 individuals comprising professors, students, and health professionals, aimed to assess the prevalence and variables related to perceived stress associated with COVID-19 (Pedrozo-Pupo et al., 2020). In total, $15 \%$ of the participants scored for high perceived stress associated with COVID-19. However, the prevalence of high perceived stress was relatively lower than previous studies performed during other epidemics, such as equine influenza (Pedrozo-Pupo et al., 2020). However, psychological responses to epidemics and outbreak management relate to several variables, such as misinformation or information overload and education, although findings regarding education can be inconsistent across different countries. For instance, less educated young people were found more vulnerable to high psychological distress during the outbreak of equine influenza in Australia (Taylor et al., 2008), whereas an opposite trend is seen in China (Qiu et al., 2020). Since PSS data is a test for well-being in general conditions, and it may be biased for stress induced by COVID-19, another method that measured COVID-SS was used.

The present study findings suggest that the intervention strategy to deal with COVID-related stress and anxiety significantly and consistently decreased the fear and increased the knowledge and subsequent growth in their knowledge. This is a new test that used for the first time to evaluate fear, knowledge, and growth mindsets in researchers during the COVID-19 era. Thus, it is not feasible to directly compare these outcomes with others in the literature that used different tests. This outcome measurement was used specifically in the context as an innovative strategy to help manage stress and increase productivity among researchers. Recent studies evaluated mental health associated with COVID-19-mediated stress and anxiety in the general population (Liu et al., 2020; Shammi et al., 2020), as well as in health workers who were involved in the treatment of COVID19 patients (Bohlken et al., 2020; Yin et al., 2020). The outcomes from all those studies showed a significant decrease in their mental health as measured by the prevalence and predictors of post-traumatic stress symptoms (PTSS) and other methods. The participants in those studies experienced high stress and anxiety, lack of sleep, and uncertainty in their future. Thus, unlike other reports, outcomes from the current study with significant improvement in mental health suggest that the strategy to manage the stress of researchers appears to be effective. However, it is important to note that participants were at low risk of becoming unemployed and were not otherwise economically affected by the pandemic. Further, no participants in this study were directly affected by the illness; neither participants nor participants' family members contracted the illness or suffered negative physical health outcomes related to the pandemic, and participants were not in high-risk groups for contracting the disease. In addition, most participants were not directly exposed to sick patients, in contrast with frontline workers. However, it can also be noted that the strategy helped to manage the wellbeing of the intervention group compared to the control group, which belonged to the same demography, age group, education level, and overall environment.

The United States has been experiencing a surge increase of anxiety prescription drugs in recent decades (Ross et al., 2019). The COVID-19 pandemic may exaggerate stress and anxiety issues in the US. The rationale of the current intervention study aims to provide a proof-of-principle to use anonymous based interventions as an alternative. Both PSS and COVID-SS scores are markers of stress management. It has been reported that group anonymous if performed properly, has the potential to turn negative stress into positive motivations (Murphy Lawrence and Hurrell Joseph, 1987). Anonymous is a widely used therapy method for treatment in alcohol, smoking, and narcotic drug abuse (Moos and Moos, 2006). In this study, the intervention emphasizes positive feedback, encouragement, and mental support to eliminate the fear, stress, and uncertainty due to COVID-19. Improvement in both PSS and COVID-SS scores 
from the intervention group, as well as relatively improved scores compared to the control group, proved the general improvement in stress conditions.

It is well-known that increased stress can significantly impair the productivity, and our mitigation strategy has improved the mental health and resulted in improved research productivity during the pandemic. Health and productivity management (HPM) was initially introduced back in the 1990s (Goetzel and Ozminkowski, 2000). The main goal of HPM was to train employees with the capability to handle crises and challenges. Stress management was also introduced at the beginning of the 21st century to promote productivity (Razavi et al., 2012). The COVID-19 pandemic is a challenge for both business and the community. Hence, training researchers to do more with few resources will benefit them in both the short-term and longterm. In the short-term, researchers are engaged in expanding their productivity portfolio by substituting wet-lab research to paper/computer-based research. The paper/computer research conducted during this period, including peer-reviewed articles and review paper writing and white/technical paper publications, are also valuable for their career. More importantly, these works, especially the process of literature research, may provide hints for future wet-lab experiments. It has been widely accepted by scientists that stepping away from the wet-lab allows them to reset and re-think the research plan to come up with more successful ideas (Harrick et al., 1986; De Bloom et al., 2014).

In the long-term, after experiencing these challenges, researchers may be more flexible and mature when facing negative situations. Negative situations include another global pandemic, wars, social conflicts, bias and discriminations, negative research results, and any other situations that may bring stress (Zarei et al., 2014).

\section{STRENGTHS AND WEAKNESSES OF THE STUDY}

Our study is unique in that it is designed to maintain well-being and improve the productivity of basic science researchers during the COVID-19 era. Although it is a small case study with only 19 participants (a limitation), the study provides preliminary evidence that the strategy has a positive impact on participants' well-being and productivity. Moreover, the study design using both cross-sectional and longitudinal studies, provides rigor to our analysis and conclusion. This study does not perform crosssectional findings for productivity, as comparing data from other basic science research groups may be unfair and difficult. Our study may be utilized, upon optimization, by a specific group to manage the well-being of their research group and maintain productivity during a challenging situation like COVID-19.

\section{IMPLICATIONS AND FUTURE PROSPECTS}

From the corporate perspective, all industries have been affected during COVID-19 pandemic, including the energy, tourism, transportation, and retail and manufacturing sectors (Fu and Shen, 2020; Shen et al., 2020). For instance, the performance of companies belonging to energy sectors is found to be negatively impacted in a study performed on the corporate performance in the energy industry by the panel data and Difference-in-Difference model (Fu and Shen, 2020). Therefore, this study could be implemented with or without modifications in every sector to improve the wellbeing of individuals and enhance their productivity. More specifically, the strategies discussed in this study could be highly beneficial when implemented in healthcare and higher education institutions.

As a vaccine for COVID-19 has not yet been approved, and due to the resurgence of the infection a future limited lock-down may yet take place. Therefore, it is important to continue to optimize the current approach if similar circumstances recur. Due to current fears for a second wave of illness during the flu season, which may further complicate the diagnosis and treatment of COVID-19, it will be beneficial to continue to monitor PSS and COVIDSS regularly. Thus, this finding will provide a potential measure for other research groups to take necessary steps in managing well-being and maintaining productivity in case the second wave leads to either full or partial lockdown and/or lab closures. Furthermore, the second wave of illness will necessitate extra caution in practicing preventive health measures. Research groups, as well as groups in other professions, could use similar empowerment sessions to encourage each other to keep healthy diets, meet exercise goals, and maintain regular sleep schedules, to the extent that their occupations allow.

Finally, the strategy discussed in this study, upon appropriate modification to tailor the situation, could also be implemented in other future challenges that we may face, e.g., new emerging or re-emerging epidemics or pandemics, financial crises, natural disasters, etc. Based on historical perspectives, either locally or globally, we face financial crises and epidemics every decade, as well as natural disasters in multiple countries almost every year (Archer and Geyer, 1982; Roser, 2019; Financial Times, 2020). Therefore, it is important to have a strategy at every institution, especially at research and educational institutions, to effectively mitigate the stress and anxiety caused by these challenges and to improve the well-being and productivity of individuals.

\section{DATA AVAILABILITY STATEMENT}

The raw data supporting the conclusions of this article will be made available by the authors, without undue reservation, to any qualified researcher.

\section{ETHICS STATEMENT}

The studies involving human participants were reviewed and approved by the Institutional Review Board, University of Tennessee Health Science Center. The 
patients/participants provided their written informed consent to participate in this study.

\section{AUTHOR CONTRIBUTIONS}

SaK conceived of the presented idea, obtained and analyzed the data, and wrote the first draft of the manuscript. SuK obtained and analyzed the data, and wrote part of the manuscript. AK obtained data, and wrote part of the manuscript. KG obtained data, and wrote part of the manuscript. KZ Obtained additional data and contributed significantly for revision of the manuscript.

\section{REFERENCES}

Alwani, S. S., Majeed, M. M., Hirwani, M. Z., Rauf, S., Saad, S. M., Shah, S. H., et al. (2020). Evaluation of knowledge, practices, attitude and anxiety of pakistans nurses towards COVID-19 during the Current Outbreak in Pakistan. medRxiv [Preprint]. 2020.2006.2005.20123703.

Anderzén, I., and Arnetz, B. B. (2005). The impact of a prospective survey-based workplace intervention program on employee health, biologic stress markers, and organizational productivity. J. Occup. Environ. Med. 47, 671-682. doi: 10.1097/01.jom.0000167259.03247.1e

Archer, A. W., and Geyer, R. (1982). Production of cyanide in a sodium nitrite poisoning case using an acid distillation screening test. J. Forensic. Sci. Soc. 22, 333-334. doi: 10.1016/s0015-7368(82)71506-3

Asensio, C., Aumond, P., Can, A., Gascó, L., Lercher, P., Wunderli, J.-M., et al. (2020). A taxonomy proposal for the assessment of the changes in soundscape resulting from the COVID-19 lockdown. Int. J. Environ. Res. Pub. Health 17:4205. doi: 10.3390/ijerph17124205

Asmundson, G. J. G., Paluszek, M. M., Landry, C. A., Rachor, G. S., Mckay, D., and Taylor, S. (2020). Do pre-existing anxiety-related and mood disorders differentially impact COVID-19 stress responses and coping? J. Anxiety Disord. 74:102271. doi: 10.1016/j.janxdis.2020.102271

Bohlken, J., Schömig, F., Lemke, M. R., Pumberger, M., and Riedel-Heller, S. G. (2020). COVID-19 pandemic: stress experience of healthcare workers - a short current review. Psychiatr. Praxis 47, 190-197. doi: 10.1055/a-1159-5551

Carter, P., Anderson, M., and Mossialos, E. (2020). Health system, public health, and economic implications of managing COVID-19 from a cardiovascular perspective. Eur. Heart J. 41, 2516-2518. doi: 10.1093/eurheartj/ehaa342

Chisholm-Burns, M. A. (2010). A crisis is a really terrible thing to waste. Am. J. Pharmaceut. Educ. 74, 19-19. doi: 10.5688/aj740219

Coronavirus-Resources-Center (2020). COVID-19 Dashboard by the Center for Systems Science and Engineering (CSSE) at Johns Hopkins University (JHU) [Online]. [Epub ahead of print]. Available online at: https://coronavirus.jhu. edu/map.html [accessed July 9, 2020).

Cutler, D. (2020). How Will COVID-19 Affect the Health Care Economy [Online]. Available online at: https://jamanetwork.com/channels/healthforum/fullarticle/2764547 [accessed Augest 8, 2020).

De Bloom, J., Ritter, S., Kühnel, J., Reinders, J., and Geurts, S. (2014). Vacation from work: A 'ticket to creativity'?: The effects of recreational travel on cognitive flexibility and originality. Tour. Manag. 44, 164-171. doi: 10.1016/j.tourman. 2014.03.013

Donthu, N., and Gustafsson, A. (2020). Effects of COVID-19 on business and research. J. Bus. Res. 117, 284-289. doi: 10.1016/j.jbusres.2020.06.008

Du, J., Dong, L., Wang, T., Yuan, C., Fu, R., Zhang, L., et al. (2020). Psychological symptoms among frontline healthcare workers during COVID-19 outbreak in Wuhan. Gen. Hosp. Psychiatry. [Epub ahead of print]. doi: 10.1016/j. genhosppsych.2020.03.011

Dubey, S., Biswas, P., Ghosh, R., Chatterjee, S., Dubey, M. J., Chatterjee, S., et al. (2020). Psychosocial impact of COVID-19. Diab. Metab. Synd. 14, 779-788. doi: 10.1016/j.dsx.2020.05.035

Epilepsy Society (2020). Empowering Yourself During COVID-19 [Online]. Available online at: http://bcepilepsy.com/blog/empowering-yourself-duringcovid19 (accessed October 15, 2020).

\section{FUNDING}

We acknowledge financial support from the National Institute of Health grant (DA047178) and The Plough Center for Sterile Drug Delivery Solutions, University of Tennessee Health Science Center.

\section{ACKNOWLEDGMENTS}

We acknowledge all the participants for their survey. We acknowledge all the participants for their survey.

Financial Times (2020). Financial Crises Occur About Once Every Decade [Online]. Available online at: https://www.ft.com/content/5148cdle-cf01-11e4-893d00144feab7de, (accessed October 15, 2020).

$\mathrm{Fu}, \mathrm{M}$., and Shen, H. (2020). COVID-19 and corporate performance in the energy industry. Energy Res. Lett. 1:12967. doi: 10.46557/001c.12967

Georgiou, N., Delfabbro, P., and Balzan, R. (2020). COVID-19-related conspiracy beliefs and their relationship with perceived stress and pre-existing conspiracy beliefs. Pers. Individ. Differ. 166:110201. doi: 10.1016/j.paid.2020.110201

Goetzel, R. Z., and Ozminkowski, R. J. (2000). Health and productivity management: emerging opportunities for health promotion professionals for the 21 st century. Am. J. Health Promot. 14, 211-214. doi: 10.4278/0890-117114.4.211

Greenberg, N., Docherty, M., Gnanapragasam, S., and Wessely, S. (2020). Managing mental health challenges faced by healthcare workers during covid19 pandemic. BMJ 368:m1211. doi: 10.1136/bmj.m1211

Guo, Q., Zheng, Y., Shi, J., Wang, J., Li, G., Li, C., et al. (2020). Immediate psychological distress in quarantined patients with COVID-19 and its association with peripheral inflammation: A mixed-method study. Brain Behavior Immunity 88, 17-27. doi: 10.1016/j.bbi.2020.05.038

Harrick, E. J., Vanek, G. R., and Michlitsch, J. F. (1986). Alternate work schedules, productivity, leave usage, and employee attitudes: a field study. Public Pers. Manag. 15, 159-169. doi: 10.1177/009102608601500206

Hendriks, T., De Jong, J., and Cramer, H. (2017). The effects of yoga on positive mental health among healthy adults: a systematic review and meta-analysis. J. Altern Complement Med. 23, 505-517. doi: 10.1089/acm.2016.0334

Heylighen, F., and Vidal, C. (2008). Getting things done: the science behind stressfree productivity. Long Range Planning 41, 585-605. doi: 10.1016/j.lrp.2008. 09.004

Hua, C.-Z., Miao, Z.-P., Zheng, J.-S., Huang, Q., Sun, Q.-F., Lu, H.-P., et al. (2020). Epidemiological features and viral shedding in children with SARS-CoV-2 infection. J. Med. Virol. doi: 10.1002/jmv.26180

Jenson, H. B. (2020). How did "flatten the curve" become "flatten the economy?" A perspective from the United States of America. Asia. J. Psychiatry 51, 102165 102165. doi: 10.1016/j.ajp.2020.102165

Jiménez, Ó, Sánchez-Sánchez, L. C., and García-Montes, J. M. (2020). Psychological impact of COVID-19 confinement and its relationship with meditation. Int. J. Environ. Res. Public Health 17:6642. doi: 10.3390/ijerph17186642

Kecojevic, A., Basch, C. H., Sullivan, M., and Davi, N. K. (2020). The impact of the COVID-19 epidemic on mental health of undergraduate students in New Jersey, cross-sectional study. PLoS One 15:e0239696. doi: 10.1371/journal. pone.0239696

Killgore, W. D. S., Taylor, E. C., Cloonan, S. A., and Dailey, N. S. (2020). Psychological resilience during the COVID-19 lockdown. Psychiatry Res. 291, 113216-113216. doi: 10.1016/j.psychres.2020.113216

Kumar, S. (2020a). Challenges with COVID-19 could bring transformational change, improve human health. Available online at: https://www. commercialappeal.com/story/opinion/2020/06/11/enhance-your-healthduring-covid-19/5336309002/ (accessed October 26, 2020).

Kumar, S. (2020b). University of Tennessee Health Sciences Center making strides in treating COVID-19 | Opinion. Available online at: https:/www.commercialappeal.com/story/opinion/2020/04/13/progressmade-finding-covid-19-vaccine/2985371001/ (accessed October 26, 2020). 
Labrague, L. J., and De Los Santos, J. (2020). COVID-19 anxiety among frontline nurses: predictive role of organisational support, personal resilience and social support. J. Nurs. Manag. 28, 1653-1661. doi: 10.1101/2020.07.16.20141069

Lai, J., Ma, S., Wang, Y., Cai, Z., Hu, J., Wei, N., et al. (2020). Factors associated with mental health outcomes among health care workers exposed to coronavirus disease 2019. JAMA Netw. Open 3:e203976. doi: 10.1001/jamanetworkopen. 2020.3976

Lee, S. A. (2020). Coronavirus Anxiety Scale: a brief mental health screener for COVID-19 related anxiety. Death Stud. 44, 393-401. doi: 10.1080/07481187. 2020.1748481

Limcaoco, R. S. G., Mateos, E. M., Fernandez, J. M., and Roncero, C. (2020). Anxiety, worry and perceived stress in the world due to the COVID-19 pandemic, March 2020. Preliminary results. medRxiv [Preprint]. 2020.2004.2003.20043992.

Liu, N., Zhang, F., Wei, C., Jia, Y., Shang, Z., Sun, L., et al. (2020). Prevalence and predictors of PTSS during COVID-19 outbreak in China hardest-hit areas: gender differences matter. Psychiatry Res. 287:112921. doi: 10.1016/j.psychres. 2020.112921

Luo, M., Guo, L., Yu, M., Jiang, W., and Wang, H. (2020). The psychological and mental impact of coronavirus disease 2019 (COVID-19) on medical staff and general public - A systematic review and meta-analysis. Psychiatry Res. 291:113190. doi: 10.1016/j.psychres.2020.113190

Ma, Y., Rosenheck, R., and He, H. (2020). Psychological stress among health care professionals during the 2019 novel coronavirus disease Outbreak: Cases from online consulting customers. Intensive Crit. Care Nurs. 20:102905. doi: 10.1016/j.iccn.2020.102905

Manch, S. E. (2020). Focusing on Resilience. Available online at: https: //www.winston.com/en/thought-leadership/focusing-on-resilience.html (accessed October 26, 2020).

Mclaren, H. J., Wong, K. R., Nguyen, K. N., and Mahamadachchi, K. N. D. (2020). Covid-19 and Women's triple burden: vignettes from Sri Lanka, Malaysia, Vietnam and Australia. Soc. Sci. 9:87. doi: 10.3390/socsci9050087

Meira, T. M., Paiva, S. M., Antelo, O. M., Guimarães, L. K., Bastos, S. Q., and Tanaka, O. M. (2020). Perceived stress and quality of life among graduate dental faculty. J. Dental Educ. 84, 1099-1107. doi: 10.1002/jdd.12241

Ming, W., Zhou, Z., Ai, H., Bi, H., and Zhong, Y. (2020). COVID-19 and air quality: evidence from China. Emerg. Markets Finan. Trade 56, 2422-2442. doi: 10.1080/1540496x.2020.1790353

Moos, R. H., and Moos, B. S. (2006). Participation in treatment and Alcoholics Anonymous: A 16-year follow-up of initially untreated individuals. J. Clin. Psychol. 62, 735-750. doi: 10.1002/jclp.20259

Murphy Lawrence, R., and Hurrell Joseph, J. (1987). Stress management in the process of occupational stress reduction. J. Manag. Psychol. 2, 18-23. doi: $10.1108 / \mathrm{eb} 043387$

New Hampshire Department of Administrative Services (2020). Perceived Stress Scale. Concord, NH: New Hampshire Department of Administrative Services.

Ornell, F., Schuch, J. B., Sordi, A. O., and Kessler, F. H. P. (2020). "Pandemic fear" and COVID-19: mental health burden and strategies. Braz. J. Psychiatry 42, 232-235. doi: 10.1590/1516-4446-2020-0008

Ozamiz-Etxebarria, N., Dosil-Santamaria, M., Picaza-Gorrochategui, M., and Idoiaga-Mondragon, N. (2020). Stress, anxiety, and depression levels in the initial stage of the COVID-19 outbreak in a population sample in the northern Spain. Cad Saude Pub. 36:e00054020. doi: 10.1590/0102-311x0005 4020

Pappa, S., Ntella, V., Giannakas, T., Giannakoulis, V. G., Papoutsi, E., and Katsaounou, P. (2020). Prevalence of depression, anxiety, and insomnia among healthcare workers during the COVID-19 pandemic: a systematic review and meta-analysis. Brain Behav. Immun. 88, 901-907. doi: 10.1016/j.bbi.2020. 05.026

Patel, A., Jernigan, D. B., and $\mathrm{nCoV}$ CDC Response Team, (2020). Initial Public Health Response and Interim Clinical Guidance for the 2019 Novel Coronavirus Outbreak - United States, December 31, 2019-February 4, 2020. MMWR. Morbid. Mortal. Weekly Rep. 69, 140-146. doi: 10.15585/mmwr. $\mathrm{mm} 6905 \mathrm{e} 1$

Pedrozo-Pupo, J. C., Pedrozo-Cortés, M. J., and Campo-Arias, A. (2020). Perceived stress associated with COVID-19 epidemic in Colombia: an online survey. Cad Saude Pub. 36:e00090520. doi: 10.1590/0102-311x00090520
Power, K. (2020). The COVID-19 pandemic has increased the care burden of women and families. Sustainability 16, 67-73. doi: 10.1080/15487733.2020. 1776561

Qiu, J., Shen, B., Zhao, M., Wang, Z., Xie, B., and Xu, Y. (2020). A nationwide survey of psychological distress among Chinese people in the COVID-19 epidemic: implications and policy recommendations. Gen Psychiatr 33:e100213. doi: 10.1136/gpsych-2020-100213

Razavi, R., Emamgholizadeh, S., and Emami, M. (2012). A survey of the relationship between stress management and workforce productivity of one of iran's industrial parks. Elixir Human Res. Mgmt. 48, 9371-9378.

Renu, K., Prasanna, P. L., and Valsala Gopalakrishnan, A. (2020). Coronaviruses pathogenesis, comorbidities and multi-organ damage - A review. Life Sci. 255:117839. doi: 10.1016/j.lfs.2020.117839

Rogers, J. P., Chesney, E., Oliver, D., Pollak, T. A., Mcguire, P., Fusar-Poli, P., et al. (2020). Psychiatric and neuropsychiatric presentations associated with severe coronavirus infections: a systematic review and meta-analysis with comparison to the COVID-19 pandemic. Lancet Psychiatry 7, 611-627. doi: 10.1016/s22150366(20)30203-0

Roser, H. R. A. M. (2019). Natural Disasters [Online]. Available online at: https: //ourworldindata.org/natural-disasters (accessed October 15, 2020).

Ross, E. L., Vijan, S., Miller, E. M., Valenstein, M., and Zivin, K. (2019). The cost-effectiveness of cognitive behavioral therapy versus secondgeneration antidepressants for initial treatment of major depressive disorder in the United States. Ann. Int. Med. 171, 785-795. doi: 10.7326/m181480

Salari, N., Hosseinian-Far, A., Jalali, R., Vaisi-Raygani, A., Rasoulpoor, S., Mohammadi, M., et al. (2020). Prevalence of stress, anxiety, depression among the general population during the COVID-19 pandemic: a systematic review and meta-analysis. Global Health 16:57. doi: 10.1186/s12992-02000589-w

Satiani, B., Zigrang, T. A., and Bailey-Wheaton, J. L. (2020). COVID-19 financial resources for physicians. J. Vascul. Surgery 72, 1161-1165. doi: 10.1016/j.jvs. 2020.04.482

Schlesselman, L. S., Cain, J., and Divall, M. (2020). Improving and restoring the well-being and resilience of pharmacy students during a pandemic. Am. J. Pharm Educ. 84:aje8144. doi: 10.5688/ajpe8144

Seyedin, H., Samadipour, E., and Salmani, I. (2019). Intervention strategies for improvement of disasters risk perception: family-centered approach. J. Educ. Health Promot 8:63.

Shammi, M., Bodrud-Doza, M., Towfiqul Islam, A. R. M., and Rahman, M. M. (2020). COVID-19 pandemic, socioeconomic crisis and human stress in resource-limited settings: A case from Bangladesh. Heliyon 6:e4063. doi: 10. 1016/j.heliyon.2020.e04063

Shen, H., Fu, M., Pan, H., Yu, Z., and Chen, Y. (2020). The impact of the COVID19 pandemic on firm performance. Emerg. Markets Fin. Trade 56, 2213-2230. doi: 10.1080/1540496x.2020.1785863

Shultz, J. M., Cooper, J. L., Baingana, F., Oquendo, M. A., Espinel, Z., Althouse, B. M., et al. (2016). The role of fear-related behaviors in the 2013-2016 west africa ebola virus disease outbreak. Curr. Psychiatry Rep. 18:104. doi: 10.1007/ s11920-016-0741-y

Spuntarelli, V., Luciani, M., Bentivegna, E., Marini, V., Falangone, F., Conforti, G., et al. (2020). COVID-19: is it just a lung disease? A case-based review. $S N$ Compr. Clin. Med. 20, 1-6. doi: 10.1007/s42399-020-00418-6

Stanton, R., To, Q. G., Khalesi, S., Williams, S. L., Alley, S. J., Thwaite, T. L., et al. (2020). Depression, Anxiety and Stress during COVID-19: associations with changes in physical activity, sleep, tobacco and alcohol use in australian adults. Int. J. Environ. Res. Public Health 17:7848. doi: 10.3390/ijerph1711 4065

Tangen, K. O., Lindmo, T., Sobrinho-Simões, M., and Johannessen, J. V. (1981). Cellular DNA content in normal human thyroid: a flow cytometric study based on frozen biopsy material. Diagn Histopathol. 4, 343-348.

Taylor, M. R., Agho, K. E., Stevens, G. J., and Raphael, B. (2008). Factors influencing psychological distress during a disease epidemic: data from Australia's first outbreak of equine influenza. BMC Public Health 8:347. doi: 10.1186/14712458-8-347

Taylor and Francis (2020). Special Issue: research on pandemics. Emerging Mark. Finance Trade 20:56. 
Titov, N., Staples, L., Kayrouz, R., Cross, S., Karin, E., Ryan, K., et al. (2020). Rapid report: Early demand, profiles and concerns of mental health users during the coronavirus (COVID-19) pandemic. Int. Intervent. 21:100327. doi: 10.1016/j. invent.2020.100327

UTHSC (2020). UTHSC COVID-19 Update: Shelter in Place [Online]. Available online at: https://www.uthsc.edu/coronavirus/campus-updates/update-03-2320-b.php (accessed March 23, 2020).

Vidya, C. T., and Prabheesh, K. P. (2020). Implications of COVID-19 pandemic on the global trade networks. Emerg. Mark. Finance Trade 56, 2408-2421. doi: 10.1080/1540496x.2020.1785426

World Health Organization (2004). Promoting Mental Health [Online]. Available online at: https://www.who.int/mental_health/evidence/en/promoting_mhh. pdf (accessed October 15, 2020).

Wu, W., Zhang, Y., Wang, P., Zhang, L., Wang, G., Lei, G., et al. (2020). Psychological stress of medical staffs during outbreak of COVID-19 and adjustment strategy. J. Med. Virol. 21:25914. doi: 10.1002/jmv.25914

Xiong, J., Lipsitz, O., Nasri, F., Lui, L. M. W., Gill, H., Phan, L., et al. (2020). Impact of COVID-19 pandemic on mental health in the general population: a systematic review. J. Affect. Disord. 277, 55-64. doi: 10.1016/j.jad.2020.08.001
Yin, Q., Sun, Z., Liu, T., Ni, X., Deng, X., Jia, Y., et al. (2020). Posttraumatic stress symptoms of health care workers during the corona virus disease 2019. Clin. Psychol. Psychother. 27, 384-395. doi: 10.1002/cpp.2477

Zarei, M. H., Razavi, H. R., and Emamgholizadeh, S. (2014). Is stress management related to workforce productivity? Iranian J. Manag. Stud. 7, 1-9.

Zarghami, A., Farjam, M., Fakhraei, B., Hashemzadeh, K., and Yazdanpanah, M. H. (2020). A report of the telepsychiatric evaluation of SARS-CoV-2 patients. Telemed. Health 20:788. doi: 10.1089/tmj.2020.0125

Conflict of Interest: The authors declare that the research was conducted in the absence of any commercial or financial relationships that could be construed as a potential conflict of interest.

Copyright (c) 2020 Kumar, Kodidela, Kumar, Gerth and Zhi. This is an open-access article distributed under the terms of the Creative Commons Attribution License (CC BY). The use, distribution or reproduction in other forums is permitted, provided the original author(s) and the copyright owner(s) are credited and that the original publication in this journal is cited, in accordance with accepted academic practice. No use, distribution or reproduction is permitted which does not comply with these terms. 